\title{
Impact of Polymer Electrolyte Membrane Degradation Products on Oxygen Reduction Reaction Activity for Platinum Electrocatalysts
}

\author{
Jason M. Christ, ${ }^{a}$ K. C. Neyerlin,, ${ }^{b, *}$ Heli Wang, ${ }^{b, *}$ Ryan Richards, ${ }^{a}$ and Huyen N. Dinh ${ }^{b, *, z}$ \\ ${ }^{a}$ Department of Chemistry and Geochemistry, Colorado School of Mines, Golden, Colorado 80401, USA \\ ${ }^{b}$ Chemical Materials and Science Center, National Renewable Energy Laboratory, Golden, Colorado 80401, USA
}

\begin{abstract}
The impact of model membrane degradation compounds on the relevant electrochemical parameters for the oxygen reduction reaction (i.e. electrochemical surface area and catalytic activity), was studied for both polycrystalline Pt and carbon supported Pt electrocatalysts. Model compounds, representing previously published, experimentally determined polymer electrolyte membrane degradation products, were in the form of perfluorinated organic acids that contained combinations of carboxylic and/or sulfonic acid functionality. Perfluorinated carboxylic acids of carbon chain length $\mathrm{C} 1-\mathrm{C} 6$ were found to have an impact on electrochemical surface area (ECA). The longest chain length acid also hindered the observed oxygen reduction reaction (ORR) performance, resulting in a $17 \%$ loss in kinetic current (determined at $0.9 \mathrm{~V}$ ). Model compounds containing sulfonic acid functional groups alone did not show an effect on Pt ECA or ORR activity. Greater than a 44\% loss in ORR activity at $0.9 \mathrm{~V}$ was observed for diacid model compounds DA-Naf (perfluoro(2-methyl-3-oxa-5-sulfonic pentanoic) acid) and DA-3M (perfluoro(4-sulfonic butanoic) acid), which contained both sulfonic and carboxylic acid functionalities.

(C) The Author(s) 2014. Published by ECS. This is an open access article distributed under the terms of the Creative Commons Attribution 4.0 License (CC BY, http://creativecommons.org/licenses/by/4.0/), which permits unrestricted reuse of the work in any medium, provided the original work is properly cited. [DOI: 10.1149/2.0921414jes] All rights reserved.
\end{abstract}

Manuscript submitted August 5, 2014; revised manuscript received October 17, 2014. Published October 30, 2014.

While there has been a concerted effort to develop membranes and electrocatalysts that significantly improve the performance of polymer electrolyte membrane fuel cells (PEMFCs), systematic studies on the magnitude and mechanism of electrocatalyst performance degradation due to contaminants arising from system components have been less prevalent. With a Department of Energy 2017 target of less than $10 \%$ voltage degradation over 5000 hours of automotive fuel cell performance, and a 2013 status of 3600 hours, improvement in the area of durability is still required. ${ }^{1}$ Air, fuel, and system derived chemical contaminants can contribute to irreversible performance loss. However, due to the fact that many factors can affect durability in a fuel cell system, it is difficult to relate the performance loss to the degradation of specific component(s). And failure mechanisms are not well understood. ${ }^{2}$

Numerous studies focusing on the performance impact of impurities found in the anode fuel stream (e.g. $\mathrm{CO}, \mathrm{CO}_{2}, \mathrm{H}_{2} \mathrm{~S}, \mathrm{NH}_{3}, \mathrm{CH}_{4}$ and $\mathrm{HCOOH}$ ), as well as common airborne contaminants present in the cathode stream (e.g. $\mathrm{SO}_{\mathrm{x}}$ and $\mathrm{NO}_{\mathrm{x}}$ ) have been conducted. ${ }^{3-11}$ In addition, various research groups have examined the impact of aromatic contaminants and environmentally common anionic and cationic species. ${ }^{12-18}$ Additional studies have investigated the performance impact of foreign metal ions (e.g. $\mathrm{Fe}^{3+}, \mathrm{Ni}^{2+}, \mathrm{Cu}^{2+}, \mathrm{Cr}^{3+}, \mathrm{Al}^{3+}$ and $\mathrm{Co}^{2+}$ ), originating from the bipolar plates and catalyst layer. ${ }^{19-25}$ Results of these studies show, in many cases, severe effects on fuel cell performance due in large to anion adsorption and irreversible chemisorption of poisoning compounds on the catalyst layer, as well as foreign cation uptake in the membrane. More recently, an investigation of species originating from balance of plant (BOP) components (e.g. structural materials and assembly aids) has shown fuel cell performance loss due to additives and other compounds that leach out of BOP materials over time. ${ }^{26-31}$ Additionally, the polymer electrolyte membrane itself could be a source of contaminants. Through the unavoidable formation of membrane chemical decomposition products arising from fuel cell operation, it is has been suggested that these compounds can migrate and adsorb into the cathode catalyst layer, leading to performance loss. The effect of membrane degradation products on the catalyst is the focus of the study presented here.

Previously, studies involving commercial membranes and model compounds have shown that when perfluorinated sulfonic acid (PFSA) membranes are exposed to peroxides and hydroxyl radicals, several chemical decomposition products can be generated. ${ }^{32-34}$ Two compounds in particular, perfluoro(2-methyl-3-oxa-5-sulfonic pentanoic)

*Electrochemical Society Active Member.

${ }^{\mathrm{z} E-m a i l: ~ h u y e n . d i n h @ n r e l . g o v ~}$ acid (DA-Naf) and perfluoro(4-sulfonic butanoic) acid (DA-3M), both shown in Figure 1, arise along with $\mathrm{HF}$ as the main membrane degradation compounds of Nafion (registered trademark of DuPont) and 3M commercial PFSA membranes, respectively. ${ }^{32,34,35}$ Along with losses in membrane conductivity and structural integrity, the aforementioned degradation products may adsorb on Pt based electrocatalysts, leading to a loss in catalyst ECA, ORR activity, or both. To date, little effort has been put forth in determining the impact PFSA chemical degradation compounds have on catalyst performance.

Much of the previous literature mentioned has focused on insitu experiments monitoring the effects contaminating species have on overall fuel cell performance. While these studies are useful for providing information on performance degradation resulting from realistic and/or real world operating conditions, they lack insight into which specific PEMFC components are affected and to what extent. Only through ex-situ experiments can the effect from anode, membrane cross-over, and oxygen diffusion limitations be eliminated and specific adsorption and kinetics occurring at the catalyst surface be determined. ${ }^{9}$ Although there have been numerous ex-situ studies investigating the impact common anions (e.g. $\mathrm{Cl}^{-}$and $\mathrm{Br}^{-}$) have on ORR activity, only a small number of studies have examined other possible fuel cell contaminants. ${ }^{8,9,36-39}$ This work thus utilizes ex-situ cyclic voltammetry (CV) and linear sweep voltammetry (LSV) using a rotating disk electrode (RDE) to investigate the effects of seven model compounds (see Figure 1) on electrocatalyst performance. As mentioned previously, model compounds DA-Naf and DA-3M represent experimentally determined degradation compounds of Nafion and $3 \mathrm{M}$ membranes respectively. ${ }^{32}$ Model compounds nonafluoro1-butanesulfonic acid (SA1) and tridecafluoro-1-hexanesulfonic acid (SA2) were chosen to gain fundamental insight on the adsorption effects solely due to sulfonic acid functional group and also to investigate the effect of fluorocarbon chain length on sulfonate anion adsorption. ${ }^{32}$ Trifluoroacetic acid (TFA), heptafluorobutyric acid (HFA), and undecafluorohexanoic acid (UFA) were chosen to gain fundamental insight on the adsorption effects solely due to carboxylic acid functional group and the fluorocarbon chain length on carboxylate anion adsorption.

In this work, we aim to expand on the understanding of how compounds formed by the degradation of membrane electrode assembly (MEA) components, specifically PEMs, affect electrocatalyst ECA, ORR activity, or both.

\section{Experimental}

DA-Naf and DA-3M were obtained in their lithium salt forms from collaborators at $3 \mathrm{M}$ at a reported purity of $>95 \%$, with the 
<smiles>O=C(O)[C-](OC(F)F)C(F)(F)F</smiles>

$\mathrm{CF}_{3}-\mathrm{CF}_{2}-\mathrm{CF}_{2}-\mathrm{CF}_{2}-\mathrm{SO}_{3} \mathrm{H}$

SA1
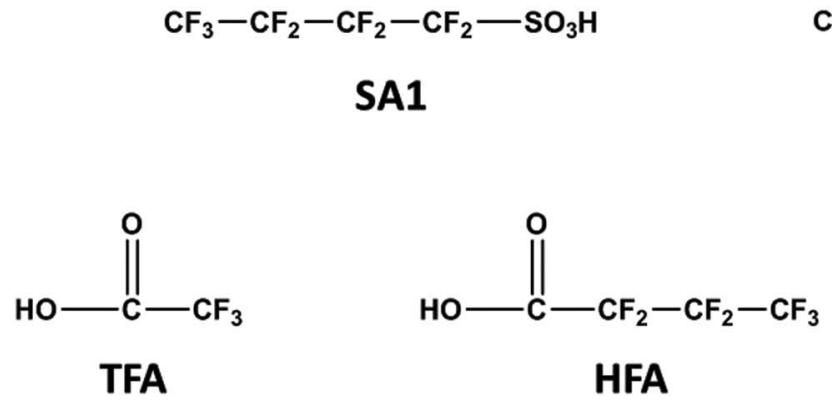<smiles>O=C(O)[Te]C#[C+]C[Sb](=O)(=O)O</smiles>

DA-3M

SA2

Figure 1. Structures and acronyms of model compounds studied.

major trace component being $\mathrm{LiF}$ (shown below to be non-adsorbing for Pt surfaces). UFA was obtained from SynQuest Laboratories with a reported purity of $99 \%$. SA1, TFA, HFA and SA2 were obtained from Sigma Aldrich with reported purities of $97 \%, 99 \%, \geq 99.0 \%$, and $\geq 98.0 \%$ respectively. All compounds were used as received. Electrochemical measurements were taken using an Autolab PGSTAT302N. A reversible hydrogen electrode (RHE) and Pt mesh were used as the reference and counter electrode respectively. Electrochemical experiments were performed in $0.1 \mathrm{M}$ perchloric acid electrolyte (diluted from $70 \% \mathrm{HClO}_{4}$ double distilled veritas grade, (GFS Chemical). Polycrystalline Pt RDE (Pine Instruments) and a Pt/Vulcan carbon (Pt/Vu) (Tec10V50E (TKK)) thin film applied to a glassy carbon RDE (Pine Instruments) were utilized as the working electrodes. Both polycrystalline Pt and glassy carbon electrodes were first polished with $0.05 \mu \mathrm{m}$ alumina slurry, then rinsed and sonicated in ultra-pure water. Pt/Vulcan carbon (Tec10V50E, Tanaka Kikinzoku Kogyo (TKK)) surfaces were prepared by applying $10 \mu \mathrm{L}$ of a catalyst ink $(7.6 \mathrm{ml}$ water, $2.4 \mathrm{ml}$ IPA, $40 \mu \mathrm{l}$ Nafion ionomer, bath sonicated in ice for $20 \mathrm{~min}$ and dried in air at $40^{\circ} \mathrm{C}$ ) to a glassy carbon surface at a $\mathrm{Pt}$ loading of $17 \mu \mathrm{g} / \mathrm{cm}^{2}$. Mass and specific activity standard deviations associated with this method are typically under $\pm 10 \%$. Experiments were performed at room temperature in a glass electrochemical cell purged with either $99.9999 \%$ pure nitrogen or $99.998 \%$ pure oxygen (Matheson Tri Gas).

After electrochemical break-in of the electrode under $\mathrm{N}_{2}$ purge (50 cycles between $0.04-1.4 \mathrm{~V}$ at $100 \mathrm{mV} / \mathrm{s}$ ), baseline ECA was determined from the integration of the hydrogen underpotential deposition (HUPD) region of the subsequent CV (final of three scans at $50 \mathrm{mV} / \mathrm{s}$ from $0.04-1.2 \mathrm{~V}$ ). The electrochemical cell was then purged with oxygen prior to obtaining baseline ORR activity measurements. For ORR measurements, the working potential was scanned in the anodic direction from $-0.01-1.0 \mathrm{~V}$ while rotating the RDE at $1600 \mathrm{rpm}$ and at a scan rate of $20 \mathrm{mV} / \mathrm{s}$; conditions traditionally used by the electrochemical community when measuring ORR activity. After baseline CVs and ORR activity were attained, a small aliquot (ca. $1 \mathrm{ml}$ ) of an aqueous solution containing the model compound of interest was injected into the electrochemical cell (containing $140 \mathrm{ml}$ of electrolyte) to yield the desired contaminant concentration. Model compounds were injected during a continuous low potential partial CV scan $(0.04 \mathrm{~V}-0.55 \mathrm{~V})$, under purge of nitrogen for a predetermined amount of time (ca. $2.5 \mathrm{~min}$ ) in order to allow the injected contaminant time to adsorb and equilibrate onto the working electrode surface. Note, the low potentials were chosen in order to maintain the chemical integrity of the injected species by preventing their possible oxidation at higher potentials. The working electrode was rotated at $2500 \mathrm{rpm}$ in order to quickly disperse the contaminant while also preventing gas bubbles from forming on the surface. After model compound CVs were obtained, the cell was again purged with oxygen, and ORR activity again measured. Model compound containing measurements were compared with baseline values taken under identical but clean conditions and following the same protocol sequence. All ORR measurements shown are raw data measured at altitude $(5,675 \mathrm{ft})$ and are corrected for ohmic resistance (iR). Because the atmospheric pressure at $5,675 \mathrm{ft}$ is $\sim 83 \mathrm{kPa}$, kinetic data determined at $0.9 \mathrm{~V}$ has been corrected for the reduction in oxygen pressure and its subsequent effect on ORR kinetics and thermodynamics. In addition a thermodynamic correction was applied to the RHE reference electrode. It is important to note however, that corrections do not alter the results since activity losses are reported relative to baseline values. Additionally, the limiting current data presented should be $\sim 82 \%$ of the range of expected limiting current attained at sea level, in accordance with the reduction in atmospheric pressure from 101.3 to $\sim 83 \mathrm{kPa}$. Eq. 1. ORR activity was measured at $0.9 \mathrm{~V}$ and normalized by the diffusion limiting current. Activities are reported as kinetic currents and calculated following Eq. 1

$$
i_{k}=\frac{i_{0.9 \mathrm{~V}} \cdot i_{\text {lim }}}{i_{\text {lim }}-i_{0.9 \mathrm{~V}}}
$$

where $i_{k}$ is kinetic current, $i_{0.9 \mathrm{~V}}$ is current measured at $0.9 \mathrm{~V}$, and $i_{\text {lim }}$ is the diffusion limiting current.

Due to solubility limitations as well as excessive bubble formation (caused from the surfactant nature of DA-Naf and DA-3M) during electrochemical measurements, model compound concentration in the cell were kept at $0.1 \mathrm{mM}$ in all experiments. Since working fuel cells incorporate dynamic electrochemical reactions and conditions, it is difficult to predict contaminant concentrations at any given time. In a previous membrane degradation study, products identified in the catalyst layer were determined to have been produced at a rate of ca. $0.02 \mathrm{mM} / \mathrm{h}$ during an open circuit potential (OCV) hold of a Nafion 112 membrane. ${ }^{40}$ Although the chosen concentration of $0.1 \mathrm{mM}$ here is likely higher than concentrations that may be found in an actual operating fuel cell, ${ }^{40}$ it is close enough to actual levels while still being able to produce observable effects on electrochemical measurements.

Model compound recovery procedure.- In order to investigate whether the poisoning impact on ECA and ORR activity was recoverable, the electrode was removed from the model compound containing cell, gently rinsed with DI water, and inserted into a clean, oxygen purged, auxiliary cell and ORR performance was again measured. 
(a)

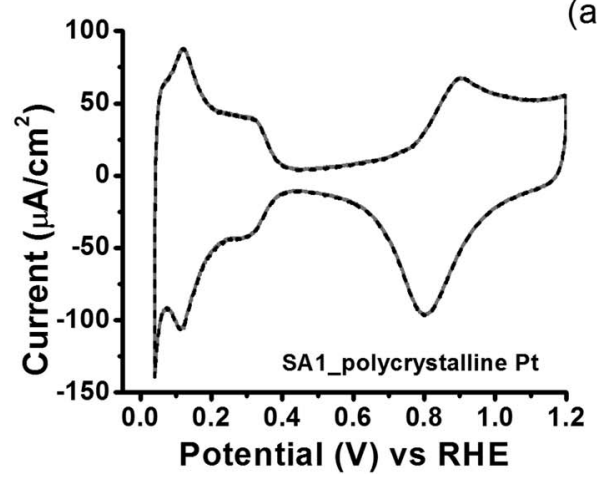

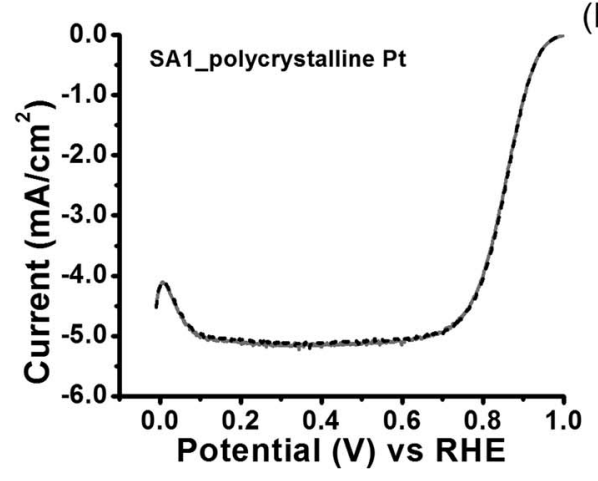

(b)

Figure 2. Impact of SA1 (0.1 mM) on CV (a) and ORR (b) for polycrystalline Pt in $0.1 \mathrm{M} \mathrm{HClO}_{4}$. Baseline scan: black dash; SA1 scan: gray solid.

Recovery CVs were subsequently performed following $\mathrm{N}_{2}$ purge. Baseline, model compound, and recovery results were compared.

\section{Results and Discussion}

Adsorption Impact of Perfluorosulfonic acids (SA1 and SA2).Electrochemical results for the model compound SA1, shown in Figure 2, overlapped with the baseline indicating that under the experimental conditions tested, the compound is non-adsorbing on polycrystalline Pt in the studied potential window (0.04-1.2 V).

When compared to baseline polycrystalline Pt performance, no changes in Pt CV or ORR performance were observed for $0.1 \mathrm{mM}$ SA1. The absence of SA1's influence on either polycrystalline Pt or $\mathrm{Pt} / \mathrm{Vu}$ (not shown) agrees with previous studies on adsorption of triflic acid $\left(\mathrm{CF}_{3} \mathrm{SO}_{3} \mathrm{H}\right)^{41,42}$ and PFSA ionomer. ${ }^{43}$ The authors reported a weak interaction, i.e. non-specific adsorption, between the sulfonate ion and Pt surface. However, there were other CV, LSV, and surface enhanced Raman spectroscopy studies that reported chemisorption of the sulfonate ion when a Nafion ionomer film was applied to a polycrystalline Pt surface. ${ }^{44-46}$ It was suggested that film crystallization from the ionomer film application method enhanced the interaction between sulfonate groups and the Pt substrate. ${ }^{43}$ Low concentrations and different structural nature (ionomer fragments in solution as opposed to an applied film) of the compound used in this study may also contribute to differences in the observations. Results of this SA1 study showed that the sulfonic acid functional group, along with the attached fluorocarbon chain, is very weakly or non-adsorbing on the polycrystalline Pt surface when SA1 is present at low concentrations $(\leq 0.1 \mathrm{mM})$.

Similarly, compound SA2 (a longer chain derivative of SA1) showed no impact on $\mathrm{CV}$ or ORR performance compared to the baseline (not shown). Thus, increasing chain length, and presumably steric hindrance and $\mathrm{pKa}$ of the molecule, did not change the adsorption or performance loss for perfluorinated sulfonic acids at low concentration.

Adsorption Impact of Perfluorocarboxylic acids (TFA, HFA, and UFA). - Impact of TFA on polycrystalline Pt CV and ORR are shown in Figure 3. Increases in both the anodic and cathodic peak currents at $0.3 \mathrm{~V}$ (Figure 3a) indicates TFA adsorption on the electrode surface and/or that TFA affects the hydrogen adsorption/desorption process. Onset of Pt oxide formation was also hindered in the presence of TFA, which shifted from $0.75 \mathrm{~V}$ to a slightly higher potential of $0.8 \mathrm{~V}$.

Although Figure 3 shows that TFA alters the hydrogen adsorption process on the Pt surface, there was no impact $(<5 \%$ loss in kinetic current) on ORR activity compared to baseline measurements (Figure 3b). An important point drawn from the TFA results is that although a compound may exhibit adsorption effects on the electrode surface during $\mathrm{CV}$ analysis, it should not necessarily be considered a contaminant/poison if that compound shows no impact on ORR activity. Also, since ORR is measured at higher potentials than those of the hydrogen adsorption process, effects observed at low potentials may not necessarily indicate an ORR performance loss.

Adsorption characteristics exhibited by TFA in this study correlate well with previously reported investigations. Through a study utilizing CV and FTIR on Pt single crystals, it was found that, similar to acetate anion, ${ }^{47,48}$ trifluoroacetic acid specifically adsorbed by its dissociated form in a bidentate bridged structure, with both oxygens specifically and reversibly bonded perpendicular to the metal surface. ${ }^{49}$ It has also been reported that acetic acid, at a concentration of $1 \mathrm{mM}$, shows a small effect on oxygen reduction for polycrystalline Pt. ${ }^{50}$ The fact that ORR performance was not affected in this current work indicates that TFA either exhibits weaker adsorption, or the low contaminant concentration $(0.1 \mathrm{mM})$ was not sufficient to produce an effect. The trifluoroacetate ion has also been reported to be less strongly bonded than the parent acetate ion, most likely due to the presence of the fluoromethyl withdrawing electron density away from the carboxylate,
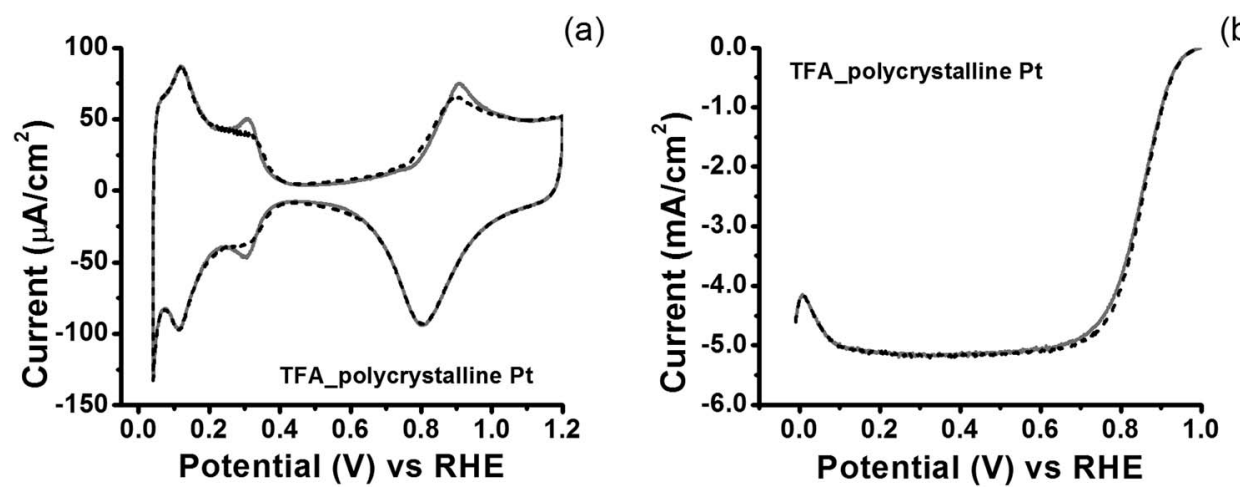

(b)

Figure 3. Impact of TFA $(0.1 \mathrm{mM})$ on CV (a) and ORR (b) for polycrystalline Pt in $0.1 \mathrm{M} \mathrm{HClO}_{4}$. Baseline scan: black dash; SA1 scan: gray solid. 

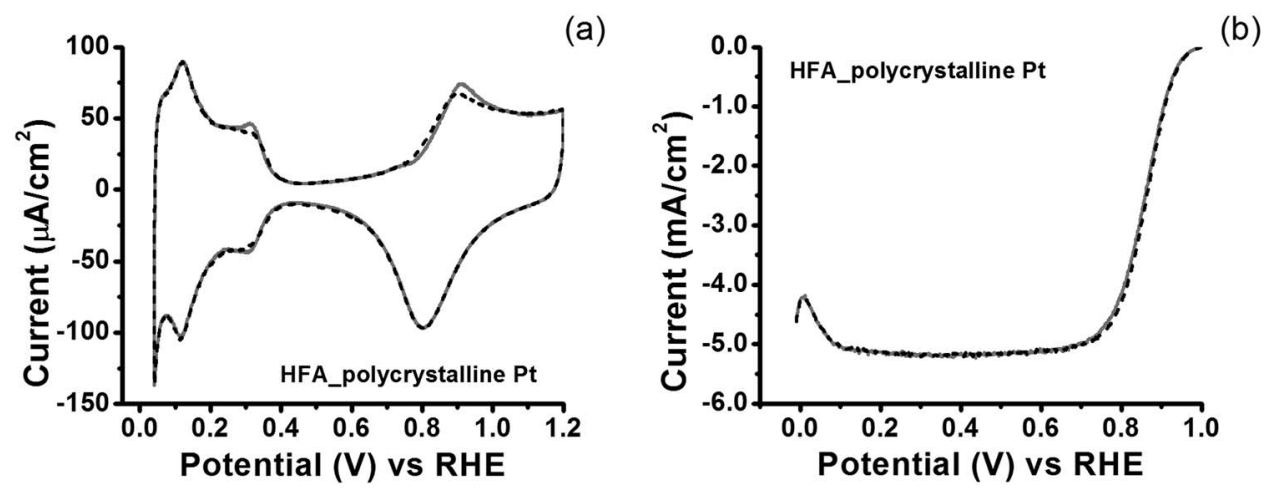

Figure 4. Impact of HFA ( $0.1 \mathrm{mM}$ ) on $\mathrm{CV}$ (a) and ORR (b) for polycrystalline Pt in $0.1 \mathrm{M} \mathrm{HClO}_{4}$. Baseline scan: black dash; SA1 scan: gray solid.

thus causing a weaker affinity for the Lewis acid character of the $\mathrm{Pt}$ surface. ${ }^{49}$ Discovery of the existence of a less compact trifluoroacetate anion adlayer when compared to acetate also provides further evidence of weaker competition with coadsorbed oxygen. ${ }^{49}$

In addition to TFA, two longer chain perfluorocarboxylic acids, HFA and UFA (Figure 1), were investigated here to probe the possible influence of the perfluorocarbon chain length on adsorption. Results for HFA (Figure 4) showed that CV scans exhibited very similar behavior to TFA. Similarly, ORR activity remained unaffected.

Figure 5 shows the impact of UFA on a polycrystalline Pt electrode. It is apparent from the CV that UFA exhibited much stronger adsorption than TFA and HFA, especially in the oxide formation region. Greater hindrance of Pt oxide formation suggests that UFA interacts with the Pt surface more strongly than TFA and HFA, while inhibiting water molecules from forming oxides on the Pt surface. A higher potential $(\sim 0.85 \mathrm{~V})$ is needed for Pt oxide formation.

When comparing the results of UFA impact on ORR activity (Figure 5) to the shorter chain analogs, it becomes evident that the length of the perfluorocarbon chain does indeed play a role in adsorption at the electrode surface. While TFA and HFA do not exhibit any impact on ORR performance, UFA inhibits the ORR significantly, inducing a $17 \%$ loss in kinetic current (transport corrected current measured at $0.9 \mathrm{~V}$ ). This suggests that after initial adsorption through the carboxylate species, further site blockage occurs through either steric effects or subsequent adsorption by the fluorocarbon chain itself. Recoverability experiments showed that the ORR performance was completely recovered (>95\%) when the contaminated electrode was gently rinsed with DI water and introduced into a clean auxiliary cell with fresh electrolyte.

In an attempt to understand the differences observed in adsorption properties among the different chain length perfluorocarboxylic acids, literature investigating the behavior of self-assembled monolayers on metal surfaces was analyzed. Studies involving self-assembled monolayers of alkanethiols on $\mathrm{Au}$ and $\mathrm{Cu}$ surfaces have shown that increases in molecular chain length are directly related to increases in both molecular ordering at the metal surface and enhanced surface blocking properties. ${ }^{51-54}$ As chain length increases, greater cohesive intermolecular forces, along with less steric mobility, allow for a more densely packed molecular arrangement at the metal surface. ${ }^{52}$ Conversely, the lower molecular ordering of short chain compounds results in a more open structure, allowing active species e.g. molecular oxygen, to more easily penetrate. ${ }^{51}$ Similar reasoning can be used for this study, as the longest chain compound (UFA) clearly exhibited the highest degree of adsorption, inhibition of oxide formation, and ORR performance loss.

Li Ion adsorption impact on Pt electrode performance.- Since model compounds DA-Naf and DA-3M were received in their lithium salt derivatives, studies were carried out in order to determine the degree of impact, if any, the lithium ion (in the form of lithium hydroxide and lithium fluoride) had on both Pt CV and ORR activity. Results (not shown) indicated no apparent impact on Pt ECA or ORR activity in the concentrations $(0.1 \mathrm{mM}-2 \mathrm{mM})$ relevant to this study and are in agreement with previous work done with alkali ions and Pt electrodes in acid electrolytes. ${ }^{55}$ Also, since the fluoride ion is known to be nonadsorbing on metal surfaces, the major trace impurity $(\mathrm{LiF})$ reported for DA-Naf and DA-3M posed no issue. ${ }^{56}$ Thus, the electrochemical results for DA-Naf and DA-3M compounds were analyzed as obtained without any compensation or normalization due to lithium ion.

Adsorption impact of perfluorinated diacids (DA-Naf and DA$3 M)$.- Diacids DA-Naf and DA-3M, shown in Figures 6 and 7 respectively, have both similar and different effects, compared to the perfluorocarboxylic acids studied. CV traces for both diacid compounds show almost identical adsorption characteristics with those for TFA and HFA. However, their impact on ORR activity differed substantially.

DA-Naf impact on ORR (see Figure 6b) showed a 44\% loss in kinetic current, suggesting a stronger ORR hindering mechanism for the

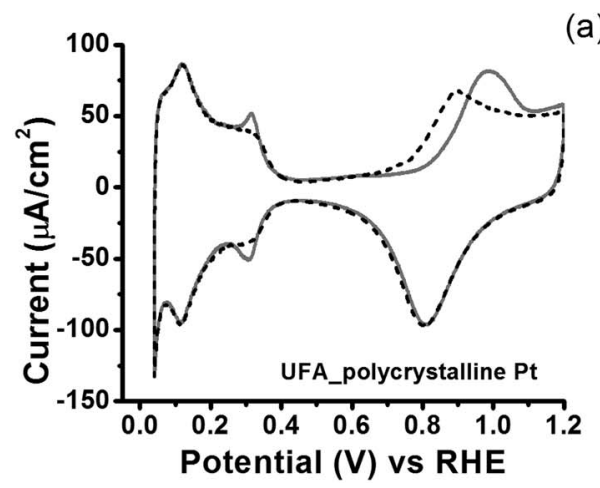

(a)

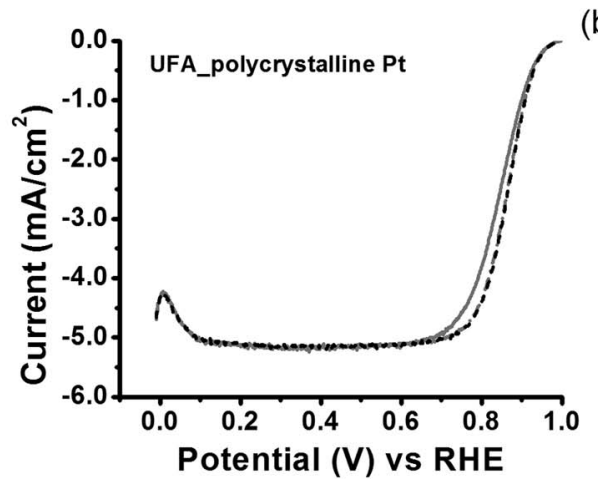

(b)

Figure 5. Impact of UFA $(0.1 \mathrm{mM})$ on CV (a) and ORR (b) for polycrystalline Pt in $0.1 \mathrm{M} \mathrm{HClO}_{4}$. Baseline scan: black dash; SA1 scan: gray solid; Recovery scan: gray dash. Note: Recovery scan overlaps with the baseline scan. 

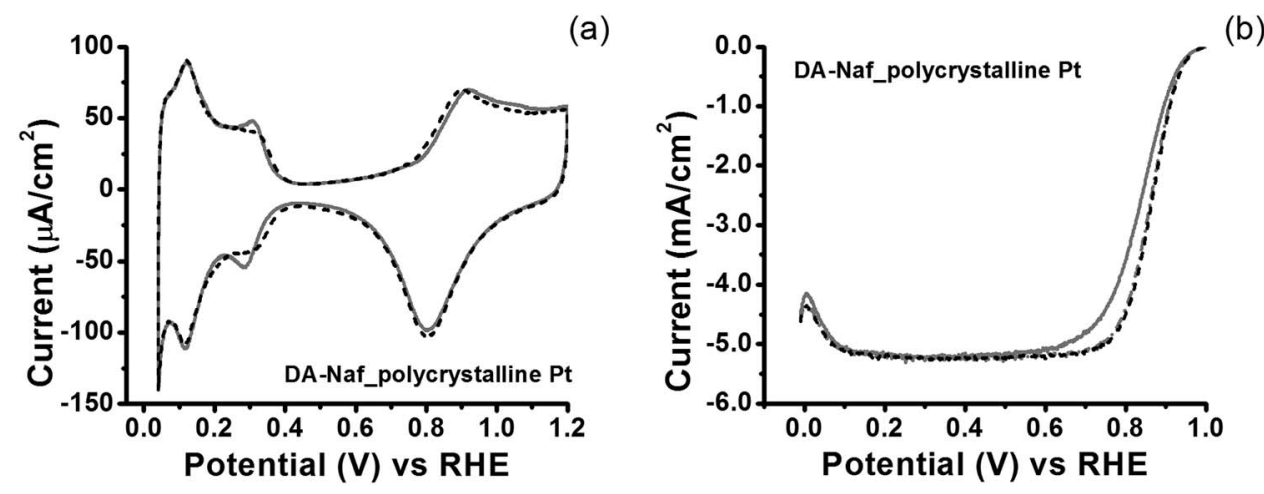

Figure 6. Impact of DA-Naf $(0.1 \mathrm{mM})$ on CV (a) and ORR (b) for polycrystalline Pt in $0.1 \mathrm{M} \mathrm{HClO}_{4}$. Baseline scan: black dash; SA1 scan: gray solid; Recovery scan: gray dash. Note: Recovery scan overlaps with the baseline scan.
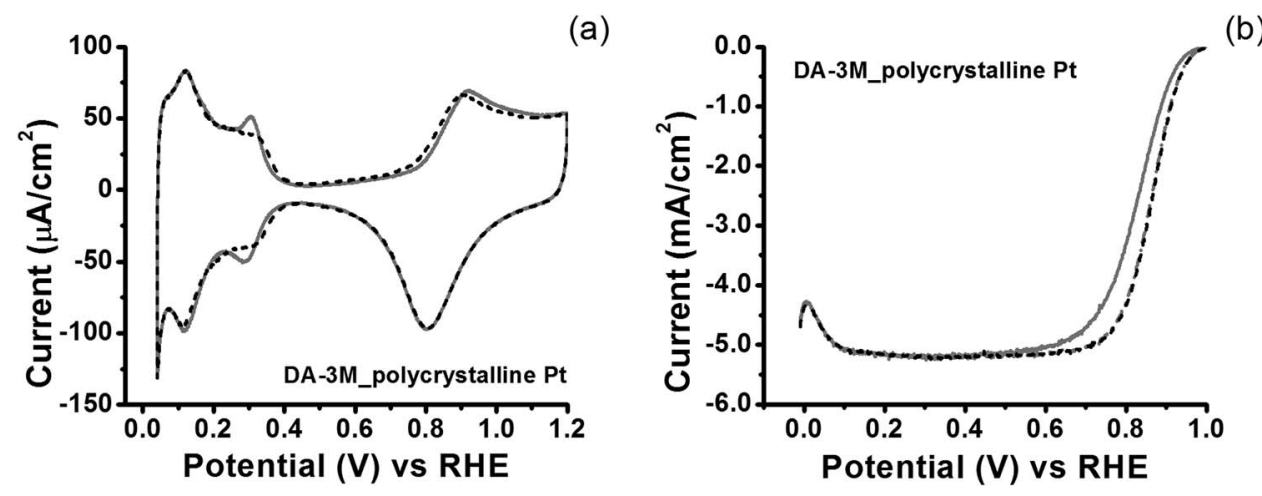

(b)

Figure 7. Impact of DA-3M $(0.1 \mathrm{mM})$ on CV (a) and ORR (b) for polycrystalline Pt in $0.1 \mathrm{M} \mathrm{HClO}_{4}$. Baseline scan: black dash; SA1 scan: gray solid; Recovery scan: gray dash. Note: Recovery scan overlaps with the baseline scan.

diacid than the monofunctional compounds discussed above. Similar to DA-Naf, a $47 \%$ loss in kinetic current was observed for DA-3M diacid adsorption for polycrystalline Pt. Recoverability experiments for both diacid model compounds showed that the ORR performance was completely recovered ( $>95 \%)$ when the contaminated electrode was gently rinsed with DI water and introduced into a clean auxiliary cell with fresh electrolyte.

The results of this study, along with the literature, ${ }^{41-43,47-49}$ showed that the perfluorinated sulfonic acids are non-adsorbing while the diacid compounds are adsorbing. Therefore, adsorption of the diacids must occur through the carboxylate end of the fluorocarbon chain. However, greater reduction in ORR activity observed in the presence of the diacid model compounds compared with the perfluorocarboxylic acids suggests that the terminal sulfonate group still plays a role, after initial adsorption of the molecule. One possible explanation is through secondary adsorption of the sulfonate anion to the Pt surface. The sulfonate anion, as mentioned previously, has been shown to effectively adsorb onto Pt surfaces under proper conditions. ${ }^{44-46}$ Initial carboxylate adsorption in this case may allow the sulfonate group to reach the surface in such a way where bond formation is more preferable (in contrast to the non-adsorbing nature of the lone perfluorinated sulfonate species reported above). Secondary bonding would thus lead to less Pt sites available for molecular oxygen to adsorb. Since there are no double or single bonds present in either DA-Naf or DA-3M, different segments of the molecules are free to rotate around their main axis, thus allowing for greater freedom to bend and adsorb through both functional groups.

An alternative explanation for the greater impact of ORR activity for the diacid model compounds arises from studies of self-assembling monolayers of alkanethiols, and the effect of terminal endgroups on surface availability for active species. Hydrophilic and polar terminal groups have shown to produce higher stabilized monolayers of alkanethiols on Au surfaces through the formation of a hydrogen bond network throughout the layer. ${ }^{52,54,57}$ In the case of DA-Naf and DA-
$3 \mathrm{M}$, sulfonate would be such a structure that would allow for hydrogen bonding to occur among adsorbed species, leading to greater surface blocking of molecular oxygen and subsequent lowering of ORR activity. It has also been reported that hydrogen bonding among terminal groups may have a stronger influence on molecular layer stability at the surface than does molecular chain length, ${ }^{52}$ which would also help explain the enhanced performance loss of the diacids compared with UFA. Lastly, possible enhanced physisorption processes occurring at the metal/solution interface due to the dual functional groups may also be contributing to the lower ORR activities observed for the perfluorinated diacid compounds. Multilayer formation occurring through intermolecular forces may also contribute to higher stability of the organic layer. A summary of the effects on polycrystalline Pt ORR performance for all compounds studied are shown in Figure 8.

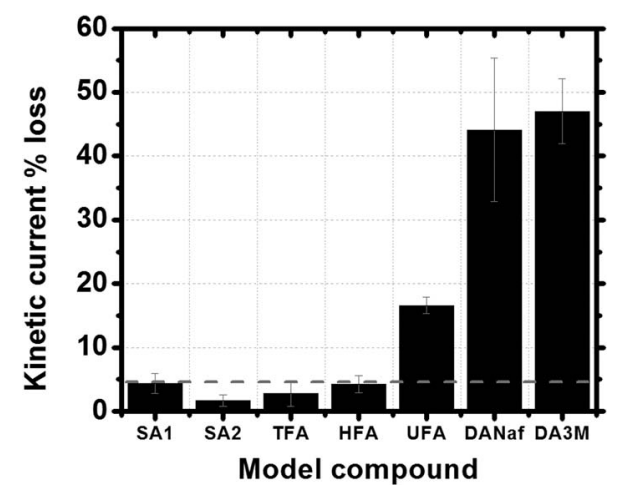

Figure 8. Summary of the effect on polycrystalline Pt ORR performance due to model compound adsorption. Control performance loss is represented by dashed line. Error bars represent standard deviations from at least three repeated experiments. 


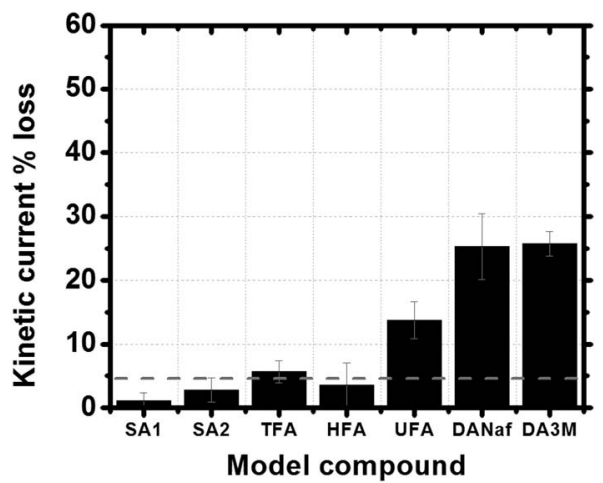

Figure 9. Summary of the effect on HSA Pt/C ORR performance due to model compound adsorption. Control performance loss is represented by dashed line. Error bars represent standard deviations from at least three repeated experiments.

Model compound electrochemical studies were also performed with a Pt/Vu (Tec10V50E, (TKK)) thin film applied to a glassy carbon RDE. Same experimental procedures were used as for polycrystalline Pt. Model compound impact on ECA followed similar behavior compared with polycrystalline Pt. Adsorption took place at similar potentials but the overall magnitude of change in the $\mathrm{CV}$ trace was less for all compounds. Similarly, ORR performance loss was dampened in the case of UFA, DA-Naf, and DA-3M. The overall trend in performance loss follows that of polycrystalline Pt. The results of the $\mathrm{Pt} / \mathrm{Vu}$ study are shown in Figure 9. The observed disparities in ORR activity loss between the two surfaces may involve the differences in surface structure among the two electrodes, with either the planar i.e. atomically flat nature of the polycrystalline surface or distribution of Pt (hkl) facets perhaps being more conducive for model compound adsorption and molecular ordering at the surface. Further studies are necessary in order to fully elucidate the impact of electrode surface structure on model compound adsorption.

Because the carbon supported Pt surface is of more practical relevance to the fuel cell community, Tafel analysis as well as RRDE studies were also conducted. Tafel curves, shown in Figure 10, were plotted for $\mathrm{Pt} / \mathrm{Vu}$ electrodes with ORR impacting model compounds DA-Naf, and DA-3M. Overall losses in activity are represented by the shifts in Tafel curves for the model compound containing scans. All changes in slope compared to baseline measurements were within the experimental error, with the greatest deviation in slope being a $9 \%$ increase for the DA-Naf curve below $0.825 \mathrm{~V}$. Tafel slope comparisons for all other model compounds and potential windows were within $5 \%$ of baseline values. Such small changes in Tafel slope indicate that the ORR mechanism is not being affected by these organic contaminates. Activity losses observed can be associated mainly with the decrease of electrochemical surface area due to model compound adsorption.

The RRDE (Pine Instruments) had a glassy carbon disk coated with a Pt/Vu thin film prepared the same way as described in the main article. The RRDE ring was polycrystalline Pt and held at $1.2 \mathrm{~V}$ during disk potential sweeps (scan rate $20 \mathrm{mV} / \mathrm{s}$ ). RRDE analysis revealed minimal increases in peroxide production compared to baseline scans for both DA-Naf and DA-3M model compounds at $0.1 \mathrm{mM}$. Model compound adsorption is likely responsible for the increase in peroxide due to Pt sites becoming blocked, leading to incomplete oxygen reduction.

Fractions of peroxide produced, shown in Figure 11, were calculated from the following equation: ${ }^{58}$

$$
\chi_{H_{2} O_{2}}=\frac{2 I_{R} / N}{I_{D}+I_{R} / N}
$$

where $\chi_{\mathrm{H}_{2} \mathrm{O}_{2}}$ is fraction of peroxide formed, $I_{R}$ is ring current, $I_{D}$ is disk current, and $N$ is the collection efficiency of the ring electrode.

Peroxides formed relative to total current were at max $1 \%$ greater for both DA-Naf and DA-3M in the disk potential window of ca.
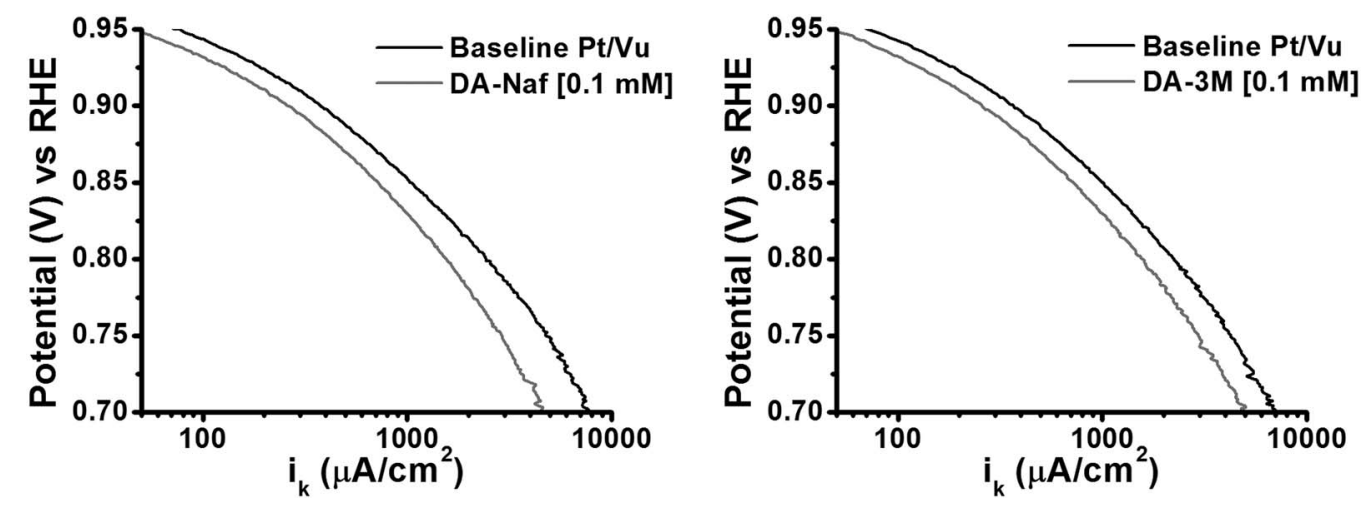

Figure 10. Tafel curve for model compound DA-Naf (left) and DA-3M (right), adsorption on Pt/Vu.
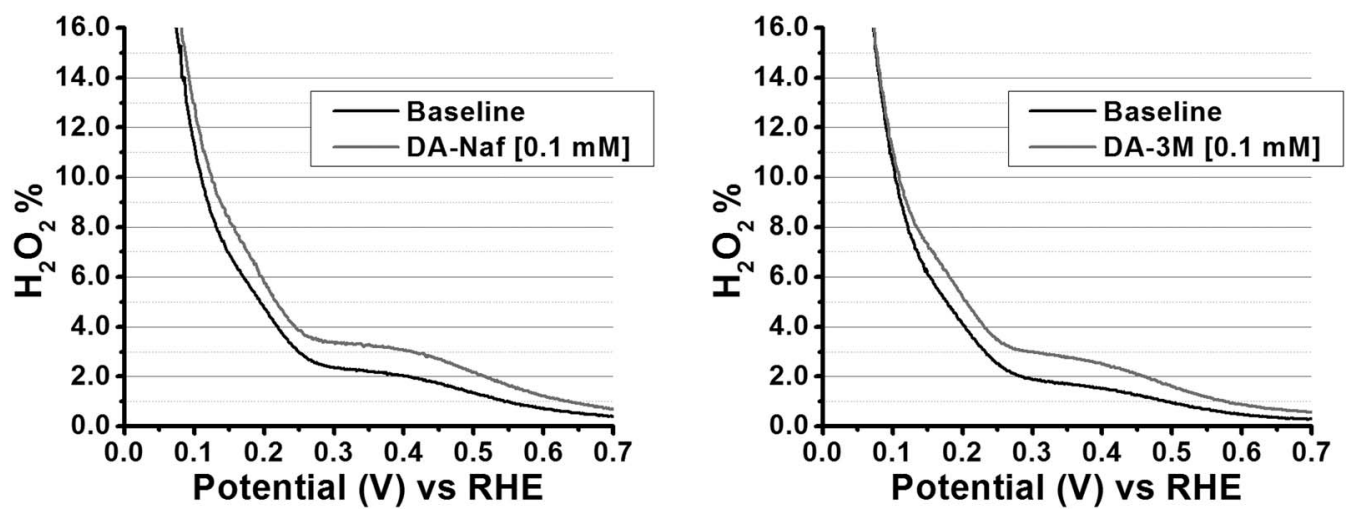

Figure 11. Fraction of $\mathrm{H}_{2} \mathrm{O}_{2}$ formation as a function of disk potential for model compounds DA-Naf (left) and DA-3M (right), adsorption on Pt/Vu. 
$0.24 \mathrm{~V}-0.44 \mathrm{~V}$. Fractions increase slightly to ca. $<2 \%$ differences when moving toward more negative potentials, and decrease when moving toward more positive potentials. In an RRDE study investigating the impact of Nafion coatings on Pt electrodes ${ }^{58}$ it was found that the sulfonate groups of the Nafion ionomer were responsible for blocking Pt sites, leading to an increase in peroxide formation rates. Sulfonate groups were suggested to be oriented to the Pt surface via water molecules in such a way that $\mathrm{O}_{2}$ adsorption on appropriate sites was not possible. A similar explanation could be applied to this work since no sulfonate adsorption peaks were observed in the CVs but appeared to show impact in diacid adsorption. Evidence is also gained here in support of the idea that the sulfonate groups of model compounds DA-Naf and DA-3M can align with the Pt surface after initial adsorption through the carboxylate anion.

\section{Conclusions}

Effects on Pt catalyst performance from seven different model compounds, representing PFSA polymer electrolyte membrane degradation products, were investigated. DA-Naf and DA-3M are experimentally determined compounds derived from the decomposition of Nafion and $3 \mathrm{M}$ polymer electrolyte membranes, respectively, Due to the diacid nature of compounds, several additional model compounds were selected to better isolate adsorption effects of the individual functional groups (sulfonic acid and carboxylic acid) as well as perfluorocarbon chain length.

SA1 and SA2 are perfluorocarbon chains with a sulfonic acid moiety and they showed no impact on either the Pt CV or ORR activity $(<5 \%$ loss in kinetic current). TFA has a carboxylic acid functionality and shows observable adsorption effects but no significant impact on ORR activity. The effect of the carboxylic acid fluorocarbon chain length was investigated. The results showed that ORR performance was not affected by the 4 carbon chain HFA compound. However, a $17 \%$ loss in kinetic current resulted when a chain of 6 carbons (UFA) was introduced. In the sulfonic acid case, however, an increase in chain length from 4 to 6 carbons did not alter electrode performance.

DA-Naf and DA-3M have both carboxylic acid and sulfonic acid functionality and showed effects on hydrogen adsorption, Pt oxide formation and ORR activity. ORR performance impacts from DA$\mathrm{Naf}(44 \%$ loss in kinetic current) and DA-3M (47\% loss in kinetic current) were greater than all other perfluorinated acids studied. Since the same functionality was present in all compounds, diacid results suggest that the sulfonate terminal group must play an additional role. One possible role is that the carboxylate adsorption allows for subsequent sulfonate adsorption. Another possibility is that a hydrogen bonding network is formed among terminal sulfonate groups, effectively blocking the surface from molecular oxygen adsorption. In-situ ATR-FTIR methods are currently being developed and future work is planned to probe this area further.

This work has shown that although performance effects due to compounds derived from the chemical decomposition of PFSA membranes may be significant in some cases, facile electrode cleaning with DI water and subsequent performance recoverability should alleviate fuel cell developers' concerns. However, due to small increases in peroxide formation from model compound adsorption at low potentials, performance and durability losses could become more severe over time. Although this study provides a fundamental look at ORR activity losses due to model compound functional group and chain length, experimental conditions i.e. temperature and catalyst loading, are different than those of an actual PEMFC. Additional studies investigating temperature, membrane, and mass transport effects are planned as future work. It is hoped that the learnings from this systematic study of functional groups and chain length can be used to understand the catalyst metal surface interactions of other organic contaminants possessing similar chemical functionality.

\section{Acknowledgments}

We gratefully acknowledge funding from the U.S. Department of Energy, Office of Energy Efficiency and Renewable Energy (EERE),
Fuel Cell Technologies Office, contract ZGB-0-4-647-1. The authors would also like to thank collaborators at $3 \mathrm{M}$ for providing materials and helpful discussions for this study.

\section{References}

1. J. Kurtz, H. Dinh, S. Sprik, G. Saur, C. Ainscough, and M. Peters, DOE Hydrogen and Fuel Cells Program: FY 2013 Annual Progress Report (2013).

2. R. Borup, J. Meyers, B. Pivovar, Y. S. Kim, R. Mukundan, N. Garland, D. Myers, M. Wilson, F. Garzon, D. Wood, P. Zelenay, K. More, K. Stroh, T. Zawodzinski, J. Boncella, J. E. McGrath, M. Inaba, K. Miyatake, M. Hori, K. Ota, Z. Ogumi, S. Miyata, A. Nishikata, Z. Siroma, Y. Uchimoto, K. Yasuda, K.-i. Kimijima, and N. Iwashita, Chemical Reviews, 107, 3904 (2007).

3. J. J. Baschuk and X. G. Li, Int. J. Energy Res., 25, 695 (2001)

4. R. Mohtadi, W. K. Lee, and J. W. Van Zee, Journal of Power Sources, 138, 216 (2004).

5. X. Zhang, H. M. Galindo, H. F. Garces, P. Baker, X. Wang, U. Pasaogullari, S. L. Suib, and T. Molter, Journal of the Electrochemical Society, 157, B409 (2010).

6. X. Zhang, U. Pasaogullari, and T. Molter, International Journal of Hydrogen Energy, 34, 9188 (2009)

7. T. Okada, in, F. N. Büchi, M. Inaba, and T. J. Schmidt, Editors, p. 323, Springer New York (2009).

8. Y. Garsany, O. A. Baturina, and K. E. Swider-Lyons, Journal of the Electrochemical Society, 154, B670 (2007).

9. M. Chen, C. Du, J. Zhang, P. Wang, and T. Zhu, Journal of Power Sources, 196, 620 (2011).

10. X. Cheng, Z. Shi, N. Glass, L. Zhang, J. J. Zhang, D. T. Song, Z. S. Liu, H. J. Wang, and J. Shen, Journal of Power Sources, 165, 739 (2007).

11. M. Nilsson, X. Karatzas, B. Lindstrom, and L. J. Pettersson, Chemical Engineering Journal, 142, 309 (2008)

12. M. C. Betournay, G. Bonnell, E. Edwardson, D. Paktunc, A. Kaufman, and A. T. Lomma, Journal of Power Sources, 134, 80 (2004).

13. K. Matsuoka, S. Sakamoto, K. Nakato, A. Hamada, and Y. Itoh, Journal of Power Sources, 179, 560 (2008)

14. W.-M. Yan, H.-S. Chu, Y.-L. Liu, F. Chen, and J.-H. Jang, International Journal of Hydrogen Energy, 36, 5435 (2011).

15. K. Kortsdottir, R. W. Lindstrom, T. Akermark, and G. Lindbergh, Electrochimica Acta, 55, 7643 (2010).

16. J. L. Rodriguez and E. Pastor, Electrochimica Acta, 45, 4279 (2000).

17. H. Li, J. Zhang, K. Fatih, Z. Wang, Y. Tang, Z. Shi, S. Wu, D. Song, J. Zhang, N. Jia, S. Wessel, R. Abouatallah, and N. Joos, Journal of Power Sources, 185, 272 (2008).

18. J. St-Pierre, Journal of Power Sources, 196, 6274 (2011).

19. M. J. Kelly, G. Fafilek, J. O. Besenhard, H. Kronberger, and G. E. Nauer, Journal of Power Sources, 145, 249 (2005)

20. M. Sulek, J. Adams, S. Kaberline, M. Ricketts, and J. R. Waldecker, Journal of Power Sources, 196, 8967 (2011).

21. H. Li, J. Gazzarri, K. Tsay, S. Wu, H. Wang, J. Zhang, S. Wessel, R. Abouatallah, N. Joos, and J. Schrooten, Electrochimica Acta, 55, 5823 (2010).

22. H. Li, K. Tsay, H. Wang, J. Shen, S. Wu, J. Zhang, N. Jia, S. Wessel, R. Abouatallah, N. Joos, and J. Schrooten, Journal of Power Sources, 195, 8089 (2010)

23. R. Jia, B. Han, K. Levi, T. Hasegawa, J. Ye, and R. H. Dauskardt, Journal of Power Sources, 196, 3803 (2011).

24. T. Y. Paul, E. A. Bonn, and B. Lakshmanan, ECS Transactions, 58, 665 (2013).

25. M. S. Opu, M. Ohashi, H.-S. Cho, C. S. Macomber, H. N. Dinh, and J. W. Van Zee, ECS Transactions, 50, 619 (2012)

26. C. Macomber, H. Wang, K. O'Neill, S. Coombs, G. Bender, B. Pivovar, and H. N. Dinh, ECS Transactions, 33, 1637 (2010).

27. H. Wang, S. Coombs, C. Macomber, K. O'Neill, G. Bender, B. Pivovar, and H. N. Dinh, ECS Transactions, 33, 1617 (2010).

28. H.-S. Cho, M. Ohashi, and J. W. Van Zee, ECS Transactions, 41, 1487 (2011)

29. C. S. Macomber, J. Christ, H. Wang, B. S. Pivovar, and H. N. Dinh, ECS Transactions, 50, 603 (2013).

30. H. Wang, C. S. Macomber, and H. N. Dinh, ECS Transactions, 50, 659 (2013).

31. H. Wang, C. Macomber, J. Christ, G. Bender, B. Pivovar, and H. N. Dinh, Electrocatalysis, 5, 62 (2014)

32. C. Zhou, M. A. Guerra, Z. M. Qiu, T. A. Zawodzinski, and D. A. Schiraldi, Macromolecules, 40, 8695 (2007)

33. L. Ghassemzadeh, K.-D. Kreuer, J. Maier, and K. Muüller, The Journal of Physical Chemistry $C, \mathbf{1 1 4}, 14635$ (2010).

34. J. Healy, C. Hayden, T. Xie, K. Olson, R. Waldo, A. Brundage, H. Gasteiger, and J. Abbott, Fuel Cells, 5, 302 (2005).

35. M. Emery, M. Frey, M. Guerra, G. Haugen, K. Hintzer, K. H. Lochhaas, P. Pham, D. Pierpont, M. Schaberg, A. Thaler, M. Yandrasits, and S. Hamrock, ECS Transactions, 11, 3 (2007).

36. N. Markovic, M. Hanson, G. McDougall, and E. Yeager, Journal of Electroanalytical Chemistry, 214, 555 (1986).

37. N. M. Markovic, H. A. Gasteiger, B. N. Grgur, and P. N. Ross, Journal of Electroanalytical Chemistry, 467, 157 (1999).

38. V. Stamenkovic, N. M. Markovic, and P. N. Ross, Journal of Electroanalytical Chemistry, 500, 44 (2001)

39. T. J. Schmidt, U. A. Paulus, H. A. Gasteiger, and R. J. Behm, Journal of Electroan alytical Chemistry, 508, 41 (2001).

40. M. Takasaki, Y. Nakagawa, Y. Sakiyama, K. Tanabe, K. Ookubo, N. Sato, T. Minamide, H. Nakayama, and M. Hori, ECS Transactions, 17, 439 (2009). 
41. M. Teliska, V. S. Murthi, S. Mukerjee, and D. E. Ramaker, J. Phys. Chem. C, 111, 9267 (2007).

42. A. Berna, J. M. Feliu, L. Gancs, and S. Mukerjee, Electrochemistry Communications, 10, 1695 (2008).

43. T. Masuda, F. Sonsudin, P. R. Singh, H. Naohara, and K. Uosaki, J. Phys. Chem. C, 117, 15704 (2013).

44. R. Subbaraman, D. Strmcnik, V. Stamenkovic, and N. M. Markovic, J. Phys. Chem. $C$, 114, 8414 (2010).

45. R. Subbaraman, D. Strmenik, A. P. Paulikas, V. R. Stamenkovic, and N. M. Markovic, Chemphyschem, 11, 2825 (2010)

46. J. Zeng, D.-i. Jean, C. Ji, and S. Zou, Langmuir, 28, 957 (2012).

47. M. Heinen, Z. Jusys, and R. J. Behm, J. Phys. Chem. C, 114, 9850 (2010).

48. A. Rodes, E. Pastor, and T. Iwasita, Journal of Electroanalytical Chemistry, 376, 109 (1994)
49. E. Pastor, A. Rodes, and T. Iwasita, Journal of Electroanalytical Chemistry, 404, 61 (1996).

50. S. Gilman, Electrochimica Acta, 65, 141 (2012).

51. D. A. Hutt and G. J. Leggett, Journal of Physical Chemistry, 100, 6657 (1996).

52. E. Cooper and G. J. Leggett, Langmuir, 14, 4795 (1998).

53. G. K. Jennings, J. C. Munro, T. H. Yong, and P. E. Laibinis, Langmuir, 14, 6130 (1998).

54. M. J. Esplandiu, H. Hagenstrom, and D. M. Kolb, Langmuir, 17, 828 (2001).

55. D. Strmcnik, K. Kodama, D. van der Vliet, J. Greeley, V. R. Stamenkovic, and N. M. Markovic, Nature Chemistry, 1, 466 (2009).

56. D. C. Grahame and B. A. Soderberg, Journal of Chemical Physics, 22, 12 (1954).

57. E. Cooper and G. J. Leggett, Langmuir, 15, 1024 (1999).

58. A. Ohma, K. Fushinobu, and K. Okazaki, Electrochimica Acta, 55, 8829 (2010). 